\title{
Recognition of combustion process irregularities in small volume displacement diesel engines with the use of non-dimensional characteristics of the vibration signal
}

The subject of the considerations described in the paper is the problem of early detection of abnormalities and damages during operation process of the turbo diesel engine with small volume displacement and direct fuel injection, which is used in modern LDV vehicles dedicated especially for urban areas, in the context of present and future requirements for a technical object diagnostics, taking into account the criteria of optimizing overall efficiency, toxic compound emission and safety of the object in real conditions of its operation. The paper presents the results of empirical research of vibroacoustic signal application to the diagnostic evaluation of correctness of short-time engine main processes. The evaluation of the combustion process variability from structural and operational abnormalities by using dimensionless estimates of a vibration process was conducted, and functional characteristics necessary to built the diagnostic algorithm in accordance with the requirements of on-board diagnostics were obtained.

Key words: $L D V$ vehicles, diesel engine, diagnostics, vibroacoustic methods, faults detection

\section{Introduction}

Social, industrial, economic and environmental changes affecting societies have driven increased mobility, with increasing interest in road, water and air transport systems of the high performance and efficiency. Contemporary vehicles and their sources of a drive have to keep up with the new demands of the user, operating conditions and law regulations.

Among the requirements particularly relevant for new engine designs is to achieve the highest possible overall efficiency and the minimum emissions of toxic exhaust gases [11]. New regulations on emissions from means of transport force vehicle manufacturers to seek solutions that will enable them to achieve lower and lower emissions limits for their internal combustion engines. As a result, vehicles with engines with lower engine displacements with increasing their useful power are increasingly common. LDV vehicles with small displacement engines are particularly important for the urban agglomeration, where the importance of toxic gas and acoustic emissions and the optimization of fuel consumption for traction conditions are paramount for such a limited area of industrial, service and social activities. For this reason, the subject matter of the paper is up to date with regard to the issues being presented, going forward with contemporary and future transport trends in the areas of urban agglomerations.

In modern transport systems the main sources of their propulsions are modern combustion engines, among which the compression-ignition engines are of a significant importance. Their widespread use in various applications of means of transport and stationary machines results from the many advantages they have. The tendency of using engines with ever smaller displacement is also related to the CI engine, which continues to be the beneficial and most preferred source of a vehicle propulsion. However, the characteristics of the internal combustion engine not only define its state functions, defined by its structural properties, but also the process and conditions of use of the object for specific purposes.
Degradation of structure of an engine and the wrongly adjusted regulating parameters may cause - deterioration of work effectiveness of a combustion engine, engine brake power decrease, reduction of the mechanical and heat efficiency, lowering of overall engine efficiency (increase of fuel consumption), growth of an toxic compounds emission, possibility of damaging to the combustion engine elements. Recognizing the importance of the proper facility use and the need to monitor constantly the correctness of all the work functions assigned to the vehicle during the design phase, it is essential to diagnose this object continually, and in particular its superior power generation system and its conversion into useful work (the internal combustion engine).

Achievements in the field of the vibroacoustic diagnostics of combustion engines allow to state that: research works on the use of vibration signal parameters for assessment of technical condition of combustion engine units or processes occurring had been carried out, research works had concerned methodical issues and modeling issues, in those research works the simple methods for describing signals and also complicated techniques of converting signal were used [14].

The above advantages of vibroacoustic methods in the context of diagnostics of compression-ignition engines of LDV vehicles make possible to assess the possibility of monitoring the correct operation of the object under traction conditions and detection of main process abnormalities and damages of specified engine components. This task was undertaken by the authors of this work by analyzing the diagnosis of combustion abnormality in small displacement $\mathrm{CI}$ engines, using non-dimensional vibration signal estimators.

\section{Methodology of the empirical process}

The overriding postulate of obtaining the unambiguous functional relations during vibroacoustic testing of machines, especially of internal combustion engines, is the proper post-processing of complex measuring signals. In this case, the proper separation of the useful vibroacoustic signal, and then the optimum selection of the characteristic 
signal characteristics from the accompanying process, eg. sensitive to damage, is of major importance $[6,7,18,19]$.

The timing of a vibroacoustic signal allows a qualitative assessment of the course of a change occurring in an object, referring to the evaluated fragment of its behavior with a specific characteristic. In this context, the degree of determinism, periodicity, occurrence or non-occurrence of certain fragments of the process and their relation to other phenomena occurring in the object is assessed. And in this case close interdependence with the kinematics of the object is necessary. The proper separation of active signal components from the recorded physical waveform and its properties relative to the source process allows the search for a diagnostic parameter in close relation with the evaluated dynamic process [3-4, 10, 12-13].

Research methodology was based on the active experiment. As the input parameters, changes in injection and combustion processes related to their correctness were taken into account. As the parameters being controlled, engine speed and torque were chosen. As the output parameters, vibration accelerations of engine head were taken into consideration. An original methodology was developed by the authors for diagnostic assessment of combustion process runs in CI engines of LDV vehicles, in order to get an accurate and non-intrusive method of combustion process description, comparable to cylinder pressure characterization. The processed data in time and frequency domains allowed to extract the components mainly related to the combustion events and these having irregularities or working cycles with misfires.

The accelerometer was put on the engine block. Such a position was selected to obtain a high vibration signal sensitivity in regard to the combustion process and a low sensitivity to the other vibrations. Placements and orientations of the accelerometer on the engine block were considered. The optimal position for the transducer was selected based on the analysis of the combustion related signal to noise ratio (passive part of a measured signal from other process sources). The research dimensions of digital signals were chosen as: $\mathrm{X}$ dimension - parallel to the diameter of a cylinder, Y dimension - perpendicular to $\mathrm{X}$ and $\mathrm{Z}$ dimensions, $\mathrm{Z}$ dimension parallel to the cylinder axis.

Values of the engine speed and load were selected within the engine operative area. Digital data was sampled during experiments once coolant and temperatures were stabilized. A software algorithms were developed by the authors and were used to manage the data post-processing analysis. The sampling frequency range during research process was $0.1 \mathrm{~Hz}$ to $25.4 \mathrm{kHz}$ for each channel of the measurement system. The sound pressure level was measured as well.

Measurement of selected parameters of the vibroacoustic process for specific engine performance was carried out in accordance with the principle of finding a reliable diagnostic parameter for accurate evaluation of the engine operating processes (injection and combustion). Such a postulate is relevant for the accurate assessment of the correctness of the functions, processes and performance of the components, in line with the criterion of ensuring optimum operation of the facility throughout its service life, taking into account its minimal environmental impact (emission of harmful exhaust gas compounds). Hence, the use of test results may take place in vehicles on-board diagnostics at traction work conditions (stationary and non-stationary).

\section{Research test stand and devices}

All researches were performed for the engine test stand conditions, and working points of the engine were chosen from the engine speed and torque operating ranges (Fig. 2).

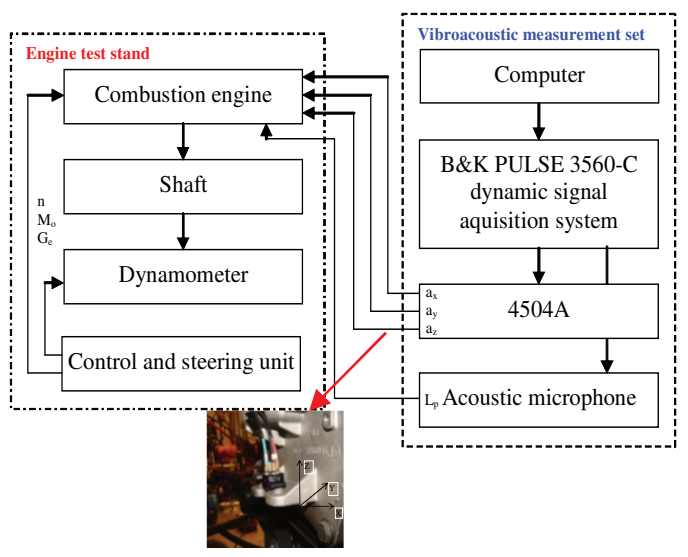

Fig. 2. The functional scheme of the measurement test stand

The compression-ignition engine taken into account in a research process is a small LDV (Light Duty Vehicle) source of a drive, that is an important share of means of transport used in urban areas. The paper considers research conducted on an common rail 4-stroke compressionignition engine of Fiat, type 1.3 JTD with the following chosen specifications [17]: engine displacement $1251 \mathrm{~cm}^{3}$, bore and stroke 69.6 x $82.0 \mathrm{~mm}$, nominal brake effective power $55 \mathrm{~kW}$ for $4000 \mathrm{rpm}$, maximum torque $170 \mathrm{~N} \cdot \mathrm{m}$ for 1750-2500 rpm, compression ratio 18.1:1, $\mathrm{CO}_{2}$ emission $113 \mathrm{~g} / \mathrm{km}$, average fuel consumption $4.24 \mathrm{dm}^{3} / 100 \mathrm{~km}$.

The placement of the vibration acceleration transducer (Bruel\&Kjær 4504A with its features: frequency 1-10000 $\mathrm{Hz}$, sensitivity $10 \mathrm{mV} / \mathrm{g}$, temperature range $-50-125^{\circ} \mathrm{C}$, resonance frequency $50 \mathrm{kHz}$ ) was located on the engine block, nearby the generated dynamic combustion processes [2]. Measurements were done for 3 perpendicular dimensions with the use of the Bruel\&Kjær Pulse 3560-C system [15].

\section{Diagnostic parameters and research conditions}

The following non-dimensional vibroacoustic signal point measures were taken into consideration in the research analyses $[1-2,5,8-9,16]$ :

a) shape coefficient

$$
\mathrm{K}=\frac{\mathrm{u}_{\mathrm{sk}}}{\mathrm{u}_{\mathrm{sr}}}=\frac{\left[\frac{1}{\mathrm{~T}} \int_{0}^{\mathrm{T}} \mathrm{u}^{2}(\mathrm{t}, \theta) \mathrm{dt}\right]^{1 / 2}}{\frac{1}{\mathrm{~T}} \int_{0}^{\mathrm{T}}|\mathrm{u}(\mathrm{t}, \theta)| \mathrm{dt}}
$$

b) peak coefficient

$$
\mathrm{C}=\frac{\mathrm{u}_{\mathrm{sz}}}{\mathrm{u}_{\mathrm{sk}}}=\frac{\mathrm{E}\left\{\begin{array}{l}
\operatorname{Max}|\mathrm{u}(\mathrm{t}, \theta)|\} \\
0<\mathrm{t}<\mathrm{T}
\end{array}\right]}{\left[\frac{1}{\mathrm{~T}} \int_{0}^{\mathrm{T}} \mathrm{u}^{2}(\mathrm{t}, \theta) \mathrm{dt}\right]^{1 / 2}}
$$


c) impulse coefficient

$$
\mathrm{I}=\frac{\mathrm{u}_{\mathrm{sz}}}{\mathrm{u}_{\mathrm{sr}}}=\frac{\mathrm{E}\left\{\begin{array}{l}
\operatorname{Max}|\mathrm{u}(\mathrm{t}, \theta)|\} \\
0<\mathrm{t}<\mathrm{T}
\end{array}\right\}}{\frac{1}{\mathrm{~T}} \int_{0}^{\mathrm{T}}|\mathrm{u}(\mathrm{t}, \theta)| \mathrm{dt}}
$$

d) clearance coefficient

$$
\mathrm{L}=\frac{\mathrm{u}_{\mathrm{sz}}}{\mathrm{u}_{\mathrm{p}}}=\frac{\mathrm{E}\left\{\operatorname{Max}_{0<\mathrm{t}<\mathrm{T}}|\mathrm{u}(\mathrm{t}, \theta)|\right\}}{\left[\frac{1}{\mathrm{~T}} \int_{0}^{\mathrm{T}}|\mathrm{u}(\mathrm{t}, \theta)|^{1 / 2} \mathrm{dt}\right]^{2}}
$$

e) kurtosis

$$
\beta=\frac{\frac{1}{\mathrm{~T}} \int_{0}^{\mathrm{T}}\left|\mathrm{u}(\mathrm{t}, \theta)-\mathrm{u}_{\mathrm{sr}}(\theta)\right|^{4} \mathrm{dt}}{\left[\frac{1}{\mathrm{~T}} \int_{0}^{\mathrm{T}}\left|\mathrm{u}(\mathrm{t}, \theta)-\mathrm{u}_{\mathrm{sr}}(\theta)\right|^{2} \mathrm{dt}\right]^{2}}
$$

Measurements were done in the following research conditions:

- termodynamic ambient conditions at the engine test stand area: $\mathrm{t}_{\mathrm{o}}=15^{\circ} \mathrm{C}$ and $\mathrm{p}_{\mathrm{o}}=1013 \mathrm{hPa}$,

- engine work conditions: stationary, for each constant engine speed values and for constant torque (7 engine speed values from the range 750-3000 rpm) and for load characteristics the torque values from $10-150 \mathrm{~N} \cdot \mathrm{m}$,

- vibroacoustic measurement conditions: vibration acceleration frequency range: $1-10000 \mathrm{~Hz}$, sampling rate: $25.6 \mathrm{kHz}$,

- placement of a vibration transducer: on the engine block (measurement in the 3 perpendicular dimensions), microphone placement - perpendicularly to the engine surface.

The measurement signals were fed to the analog inputs of the data acquisition card. Measurement signals were filtered inside the card with the help of analog and digital filters and then were converted from analog to digital. The signals obtained in the data acquisition card in a digital form were stored in a computer memory. The recorded all time history courses of the measurement signals were subjected to the time selection process. In the above selection all recorded signals were divided into signal sequences including single working cycles of the internal combustion engine.

\section{Description of the research conditions and process}

Measurements were made for different engine speed and torque values according to the following characteristics:
a) $y_{1}=f\left(N_{e}\right)$ - screw characteristics;
b) $y_{2}=f\left(n, M_{o}=\right.$ const. $)$ - speed characteristics for con- stant torque values,
c) $y_{3}=f\left(M_{o}, n=\right.$ const. $)-$ load characteristics.

The following diagnostic parameters were taken into account in the analysis:

a) parameters of work processes: fuel injection pressure $\left(\mathrm{p}_{\mathrm{inj}}\right)$ and cylinder pressure $\left(\mathrm{p}_{\mathrm{c}}\right)$, fuel consumption $\left(\mathrm{G}_{\mathrm{e}}\right.$, $\left.\mathrm{g}_{\mathrm{e}}\right)$, total efficiency $(\eta)$,

b) parameters of accompanying processes: vibration accelerations in three dimensions $\left(\mathrm{a}_{\mathrm{x}}, \mathrm{a}_{\mathrm{y}}, \mathrm{a}_{\mathrm{z}}\right)$, sound pressure level $\left(\mathrm{L}_{\mathrm{p}}\right)$.

\section{Assessment of the measurements results}

Analysis of the engine working area during testing included the following overall engine efficiency ranges for the characteristics:

- partial power: $22-27 \%$,

- load: $14-37 \%$,

- screw: 19-38\%.

If the engine speed values increase equivalent value of the sound pressure level and instantaneous peak sound pressure level are also raised (Fig. 3) - for $\mathrm{L}_{\text {Aeq }}$ increase up to $44 \%$ (depends from the working point). It means that the intensity of the dynamic processes taking place in internal combustion engines rises and level of the energy release from the process is transferred by the block material structure.

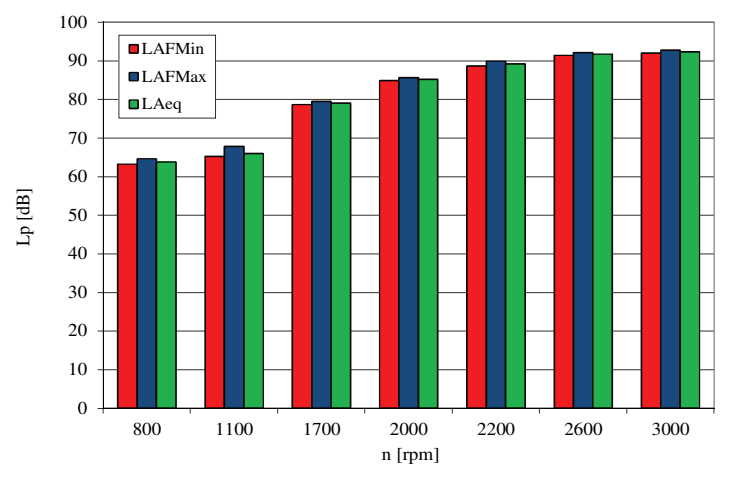

Fig. 3. The equivalent acoustic pressure level $\left(\mathrm{L}_{\text {Aeq }}\right)$ changes for different engine speeds

Observing the mean, RMS, peak, peak-to-peak point estimators of the vibration accelerations one can find that there is a strict function relation between the engine speed increase and the change of the above point measure (Figs 4-6). The point measures values, obtained for a combustion process, increases when engine speed rises, no matter what measurement dimension is considered. The highest values were obtained for $\mathrm{Z}$ dimension. Comparing such results with the peak and peak-to-peak values for the combustion process time run sections it is obvious the above two dimensional point measures of the vibration accelerations have the highest sensitivity for combustion process changes in the relation with the engine speed factor.

Comparing of all point measures taken into consideration for a $\mathrm{Z}$ dimension one can perceive the peak and peakto-peak values are the most sensitive measures for combustion process changes resulting from engine speed increase. That means also the incorrect processes that might appear in the normal combustion engine operation will be unequivocally detected and described. 


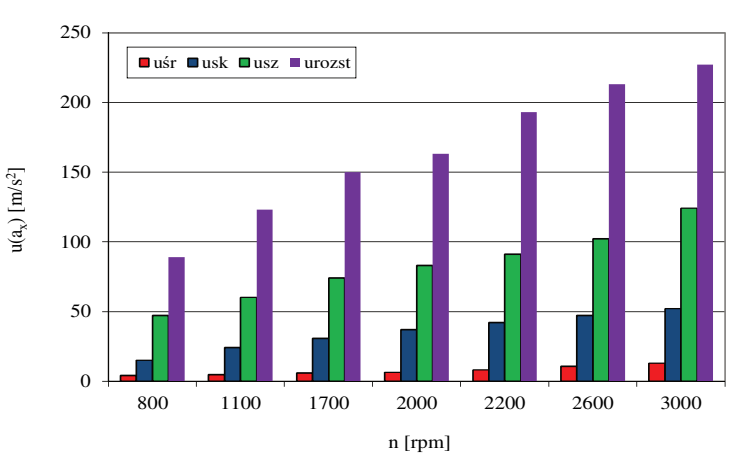

Fig. 4. Mean, RMS, peak and peak-to-peak value of vibration accelerations for $\mathrm{X}$ dimension and different engine speeds

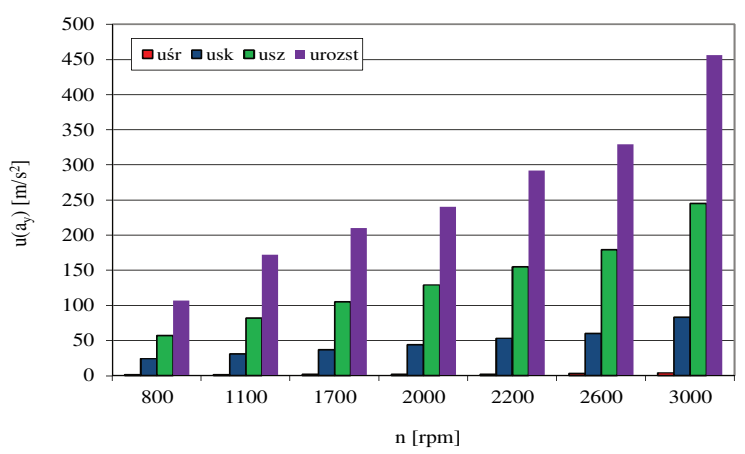

Fig. 5. Mean, RMS, peak and peak-to-peak value of vibration accelerations for $\mathrm{Y}$ dimension and different engine speeds

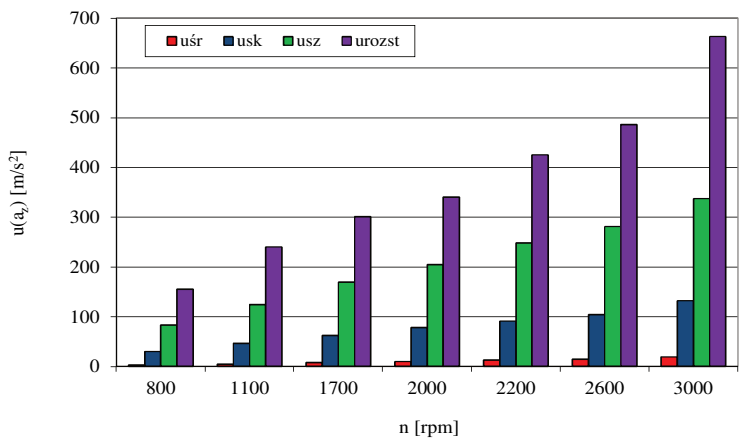

Fig. 6. Mean, RMS, peak and peak-to-peak value of vibration accelerations for $\mathrm{Z}$ dimension and different engine speeds

Determination of the variance function of the mentioned dimensional point estimates for empirical data with respect to the engine speed indicates simple mathematical functions that can be described for $\mathrm{Z}$ dimension as:

$$
\begin{gathered}
\mathrm{L}_{\text {Aeq }}(\mathrm{n})=16.83 \ln (\mathrm{n})+60.496\left(\mathrm{R}^{2}=0.95\right) \\
\mathrm{a}_{\mathrm{z}, \mathrm{sk}}(\mathrm{n})=16.107 \mathrm{n}+13.143\left(\mathrm{R}^{2}=0.99\right) \\
\mathrm{a}_{\mathrm{z}, \mathrm{sz}}(\mathrm{n})=41.25 \mathrm{n}+41.571\left(\mathrm{R}^{2}=0.99\right) \\
\mathrm{a}_{\mathrm{z}, \text { rozst }}(\mathrm{n})=76.429 \mathrm{n}+67.143\left(\mathrm{R}^{2}=0.96\right)
\end{gathered}
$$

However, the question is how sensitive the nondimensional vibroacoustic indicators are to the changes in engine speed. They are the point estimators independent of the momentary value of vibration amplitude. In addition, they allow to study the effects of the main process and its amplitude and energy values on the assumption of periodicity and relatively faithful reflection of the vibration characteristics for the engine fuel injection and combustion pro- cess. This makes it is possible to assess indirectly the determinants of the vibroacoustic process with the diagnostic nature, taking into account the reliability and unambiguity of the diagnosis (Figs 7-11).

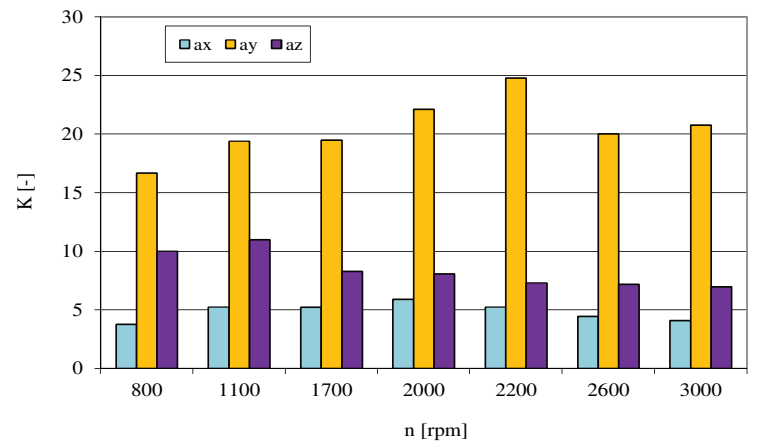

Fig. 7. Shape coefficient of vibration accelerations for $\mathrm{X}, \mathrm{Y}$ and $\mathrm{Z}$ dimensions and different engine speeds

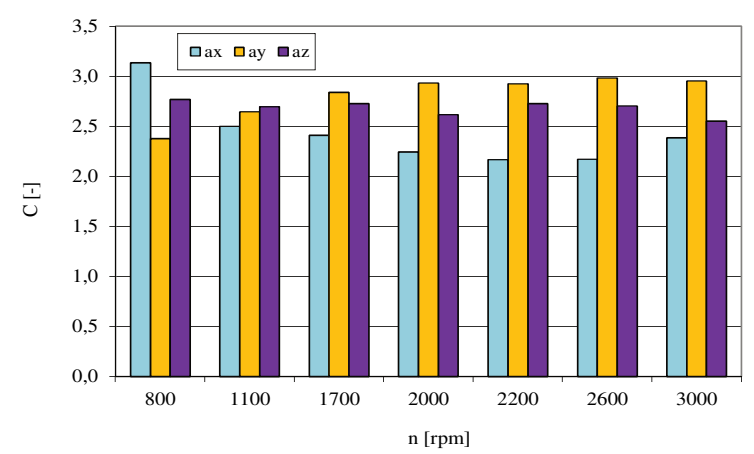

Fig. 8. Peak coefficient of vibration accelerations for $\mathrm{X}, \mathrm{Y}$ and $\mathrm{Z}$ dimensions and different engine speeds

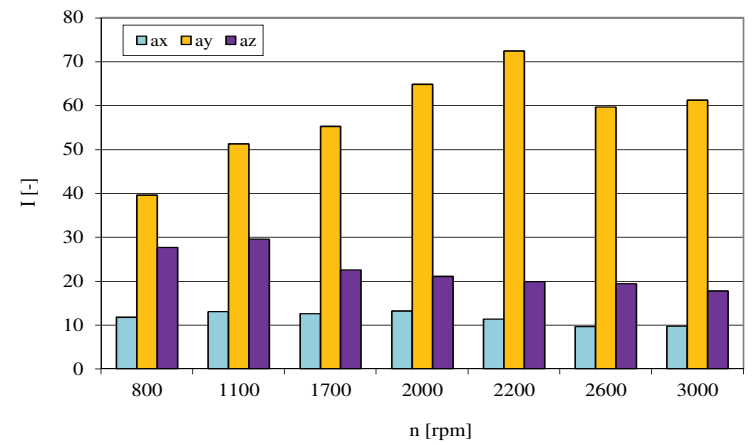

Fig. 9. Impulse coefficient of vibration accelerations for $\mathrm{X}, \mathrm{Y}$ and $\mathrm{Z}$ dimensions and different engine speeds

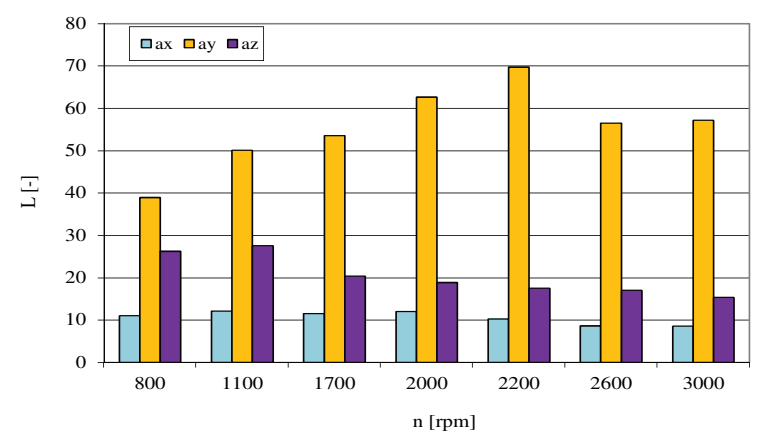

Fig. 10. Clearance coefficient of vibration accelerations for $\mathrm{X}, \mathrm{Y}$ and $\mathrm{Z}$ dimensions and different engine speeds 


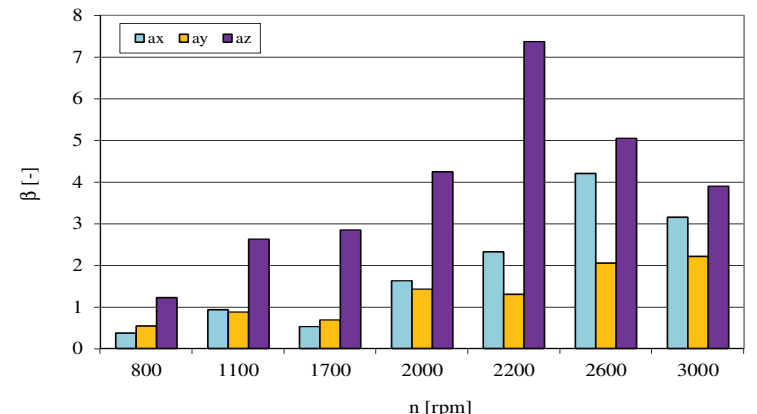

Fig. 11. Kurtosis of vibration accelerations for $\mathrm{X}, \mathrm{Y}$ and $\mathrm{Z}$ dimensions and different engine speeds

The obtained waveforms of the selected nondimensional measures of vibroacoustic process are not as clear as in the case of the first ones. Undoubtedly, the shape, pulse and slope coefficients for the $\mathrm{Z}$ direction have been found to be sensitive to combustion but with less reflection.

$$
\begin{gathered}
\mathrm{K}_{\mathrm{az}}(\mathrm{n})=-0.6323 \mathrm{n}+10.909\left(\mathrm{R}^{2}=0.80\right) \\
\mathrm{C}_{\mathrm{az}}(\mathrm{n})=-0.0225 \mathrm{n}+2.7732\left(\mathrm{R}^{2}=0.43\right) \\
\mathrm{I}_{\mathrm{az}}(\mathrm{n})=-5.874 \ln (\mathrm{n})+29.684\left(\mathrm{R}^{2}=0.82\right) \\
\mathrm{L}_{\mathrm{az}}(\mathrm{n})=-2.0206 \mathrm{n}+28.448\left(\mathrm{R}^{2}=0.86\right) \\
\beta_{\mathrm{az}}(\mathrm{n})=-0.1186 \mathrm{n}^{3}+1.1617 \mathrm{n}^{2}-2.147 \mathrm{n} \\
+2.5369\left(\mathrm{R}^{2}=0.84\right)
\end{gathered}
$$

Analysis of the dimensionless estimates along with the increase of the engine speed indicates the uniqueness of the changes for the $\mathrm{Z}$ dimension for the shape, impulse and clearance coefficients. For the Y dimention, both the shape, the peak, impulse and the clearance are similar to the index change (increase in the measure to $n=2200 \mathrm{rpm}$ ). The above increase in value for a $\mathrm{Z}$ dimension is due to the significant increase in amplitude and energy emitted by the accompanying process from the working process. This results in a change in peak, RMS and mean values. The first of them concerns the increase of the impulse interaction of the dynamic process on the structure of the object, the second refers to the energy transfer from the main process to the object, the mean value on the increase, the amplitude of the signal, the energy emitted during the combustion process and the influence of the combustion nature of the increased fuel dose on the vibration acceleration time signal. Selecting a $\mathrm{Z}$ dimension as sensitive for combustion of the mixture in the cylinder determines the choice of $\mathrm{K}, \mathrm{I}$ and $\mathrm{L}$ coefficients, according to the criterion of their uniqueness.
The $\mathrm{K}$ factor determines the shape of a periodic waveform, and I factor how much the amplitude pulse value is relevant throughout the sample signal reflecting the dynamic process. The peak factor illustrates the relationship between the peak value and the global level of the whole measurement. Increasing the value of the clearance coefficient shows the accumulation of energy or occurs when the scattering of the measurement data changes.

Kurtosis is a measure of the flattening of a characteristic value distribution. It specifies the location and concentration of data values near the mean estimator. It occurs in the form of a fourth-degree central torque, referenced to a standard deviation raised to the fourth power. The higher the value of the kurtosis, the greater is the concentration of the population of data around the mean value (the slope of the distribution curve is greater). Its small value gives the opposite effect, which means a greater spread of values. The above indicator is higher with increasing rotational speed, showing the intensification of the dynamic impact from the combustion process (increase of the central torque), until the amount of emitted energy affects the average acceleration value.

\section{Conclusions}

The presented work is a new research carried out by its authors within the study of the influence of selected characteristics for $\mathrm{CI}$ engine with small engine displacement and relatively high brake power on non-dimensional vibroacoustic parameters. Comparison of selected dimensional and non-dimensional points measures allowed the diagnostic parameter and its reliability to be evaluated for the study of such vehicle sources of a drive, and its results can be used in their assessment in the real vehicles streams.

Due to the area of these measures analysis, limited to the field of time and value of the process, frequency analysis is of major importance. Modern engine diagnostics requires more and more detailed parametric and functional assessments. Changes to the regulations for vehicles of this category will affect their choice with a multi-criterion rating. Reliable characteristics and estimators will be put to the future diagnostic algorithms, which will be able to do the complex evaluation of the real technical state of objects even in non-stationary work conditions. That is why the specified diagnostic algorithms that use non-dimensional vibration signal point measures and improved frequency domain analyses should be created in the on-board diagnostics procedures basing on such methods of an empirical signal assessment.

\section{Nomenclature}

$\begin{array}{ll}\text { a } & \text { vibration acceleration } \\ \beta & \text { kurtosis } \\ \mathrm{C} & \text { peak coefficient } \\ \mathrm{CI} & \text { compression-ignition } \\ \mathrm{CO}_{2} & \text { carbon dioxide } \\ \eta & \text { overall efficiency } \\ \mathrm{G}_{\mathrm{e}} & \text { stream mass of fuel consumption } \\ \mathrm{g}_{\mathrm{e}} & \text { specific fuel consumption }\end{array}$

I impulse coefficient

K shape coefficient

L clearance coefficient

LDV light duty vehicle

$\mathrm{L}_{\mathrm{p}} \quad$ sound pressure level

$\mathrm{M}_{\mathrm{o}}$ torque

$\mathrm{n} \quad$ engine speed

$\mathrm{N}_{\mathrm{e}} \quad$ engine brake power 
$\mathrm{p}_{\text {inj }} \quad$ fuel injection pressure

$\mathrm{p}_{\mathrm{o}}$ ambient pressure

$\theta \quad$ lifetime of an object

$\mathrm{t}$ duration of dynamic processes

T signal period

$\mathrm{t}_{\mathrm{o}} \quad$ ambient temperature $\mathrm{u}(\mathrm{t}, \theta)$ instantaneous signal value

$\mathrm{u}_{\mathrm{p}} \quad$ square root signal value

$\mathrm{u}_{\mathrm{sr}} \quad$ mean signal value

$\mathrm{u}_{\mathrm{sz}} \quad$ peak signal value

$\mathrm{u}_{\mathrm{sk}} \quad$ root mean square signal value

\section{Bibliography}

[1] BARTELMUS, W., ZIMROZ, R. A new feature for monitoring the condition of gear- boxes in nonstationary operating conditions. Mechanical Systems and Signal Processing. 2009, 23, 1528-1534.

[2] CEMPEL, C. Vibroacoustic machines diagnostics. National Scientific Publishing Houses, Warsaw 1989.

[3] CZECH, P., ŁAZARZ, B., WOJNAR, G. Detection of local gears of gear wheel gear using artificial neural networks and genetic algorithms. ITE, 2007, Radom.

[4] CZECH, P., MADEJ, H. Application of cepstrum and spectrum histograms of vibration engine body for setting up the clearance model of the piston-cylinder assembly for RBF neural classifier. Maintenance and Reliability. 2011, 4, 15-20.

[5] CZECH, P., WOJNAR, G., FOLĘGA, P. Vibroacoustic diagnosing of disturbances in the car ignition system by amplitude estimates. Scientific Journals of Silesian University of Technology. Series: Transport. 2014, 83, 1904, 59-64.

[6] DESBAZEILLE, M., RANDALL, R.B., GUILLET, F. et al. Model-based diagnosis of large diesel engines based on angular speed variations of the crankshaft. Mechanical Systems and Signal Processing. 2010, 5, 1529-1541.

[7] FIGLUS, T. Diagnosing the engine valve clearance, on the basis of the energy changes of the vibratory signal. Maintenance Problems. 2009, 1, 75-84.

[8] KORBICZ, J., KOŚCIELNY, J. Modeling, diagnostics, and mastering processes. DiaSter implementation. Scientific and Technical Publishing House. Warsaw 2010.

[9] KORBICZ, J., KOŚCIELNY, J.M., KOWALCZUK, Z., CHOLEWA, W. Process diagnostics. Science and Technology Publishing House. 2002, 3.

[10] MADEJ, H., CZECH, P. Discrete wavelet transform and probabilistic neural network in IC engine fault diagnosis. Maintenance and Reliability. 2010, 4, 47-54.

Prof. Jerzy Merkisz, DSc., DEng. - Faculty of Machines and Transport at Poznan University of Technology.

e-mail: Jerzy.Merkisz@put.poznan.pl

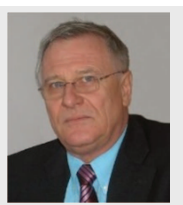

[11] MERKISZ, J., JACYNA, M., MERKISZ-GURANOWSKA, A., PIELECHA, J. The parameters of passenger cars engine in terms of real drive emission test. Archives of Transport. 2014,. 32(4), 43-50.

[12] PUŠKÁR, M., BIGOŠ, P., PUŠKÁROVÁ, P. Accurate measurements of output characteristics and detonations of motorbike high-speed racing engine and their optimization at actual atmospheric conditions and combusted mixture composition. Measurement. 2012, 45, 1067-1076.

[13] QINGHUA, W., YOUYUN, Z., LEI, C., YONG-SHENG, $\mathrm{Z}$. Fault diagnosis for diesel valve trains based on nonnegative matrix factorization and neural network ensemble. Mechanical Systems and Signal Processing. 2009, 23, 16831695.

[14] SZYMAŃSKI, G.M., TOMASZEWSKI, F. Application of impact tests to diagnose internal combustion engines. Proceedings of the 17th International Congress on Sound and Vibration. 2010, 2, 1282-1289.

[15] www.bksv.com.

[16] www.neur.am.put.poznan.pl/dwm/3.5.3.pdf.

[17] www.springerprofessional.de.

[18] YADAV, S.K., KALRA, P.K. Fault diagnosis of internal combustion engine using empirical mode decomposition. Proceedings of the IEEE 6th International Symposium on Image and Signal Processing and Analysis. ISPA 2009, 4046.

[19] YILDIRIM, H., ÇINAR, A., SAYLI, O., KOYLU, H. Vibration and noise analysis of an engine fuelled with diesel and biodiesel blends. ICAME'15: International Conference on Advances in Mechanical Engineering. 13th-15th May 2015, Istambul.

Marek Waligórski, DSc., DEng. - Faculty of Machines and Transport at Poznan University of Technology.

e-mail: Marek.Waligorski@put.poznan.pl

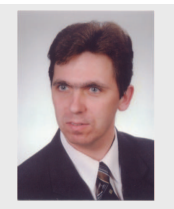

